\title{
Coordinating a two-echelon supply chain under inflation and time value of money
}

\author{
B.C. Giri ${ }^{\mathbf{a}^{*}}$ and S. Bardhan ${ }^{\mathrm{a}}$
}

${ }^{a}$ Department of of Mathematics, Jadavpur University, Kolkata - 700 032, India

\begin{tabular}{|c|c|}
\hline A R T I C LE I N FO & A B S T RACT \\
\hline $\begin{array}{l}\text { Article history: } \\
\text { Received } 11 \text { April } 2010 \\
\text { Received in revised form } \\
\text { June, } 5,2011 \\
\text { Accepted } 9 \text { June } 2011 \\
\text { Available online } \\
\text { 12 June } 2011 \\
\text { Keywords: } \\
\text { Supply chain } \\
\text { Inflation }\end{array}$ & $\begin{array}{l}\text { In the current global economic scenario, inflation plays a vital role in deciding optimal pricing } \\
\text { of goods in any business entity. This paper develops a two-echelon (manufacturer-buyer) } \\
\text { supply chain model taking into account inflation and time value of money. The present value of } \\
\text { the total cost of the supply chain is derived when the manufacturer produces a number of lots, } \\
\text { the sum of which is equal to the buyer's total demand over a finite time horizon and the } \\
\text { manufacturer's each production lot is delivered to the buyer in } n \text { shipments. The optimal } \\
\text { solution of the model is obtained for a numerical example after some adjustments (required to } \\
\text { exhibit feasibility) in the derived solution. Sensitivity analysis is also carried out in order to } \\
\text { examine the effects of changes in model-parameters on the optimal solution. }\end{array}$ \\
\hline
\end{tabular}

\section{Introduction}

Supply chain management has been the topic of interest to many Operations Research/Management Science researchers quite for a long time. Research in this area is influenced by the realization of company managers that a high level of coordination among the players of a supply chain is required in order to meet growing customer demand and services and thereby enhance company profits. In the case of a single-vendor single-buyer supply chain, the idea of optimizing the joint total cost was introduced by Goyal (1976). Banerjee (1986) developed the model by incorporating a finite production rate and following a lot-for-lot policy for the vendor. Later, Goyal (1988) proposed a more general joint economic lot-sizing model by relaxing Banerjee's lot-for-lot assumption. Lu (1995) specified the optimal production and shipment policies when the shipment sizes are equal. He also relaxed the assumption of completing a whole batch before starting shipment proposed by Goyal (1988). Goyal (1995) developed a model where successive shipment sizes increase by a ratio equal to the production rate divided by the demand rate. He derived an expression for the optimal first shipment size as a function of the number of shipments. Later, Hill (1997) extended this idea one step further by considering the geometric growth factor as a decision variable. He suggested a solution method based on an exhaustive search for both the growth factor and the number of shipments within certain ranges.

\footnotetext{
* Corresponding author. Tel.: +91 3324146717

E-mail: bibhas_pnu@yahoo.com (B. C. Giri)

(c) 2011 Growing Science Ltd. All rights reserved. doi: $10.5267 /$ j.ijiec.2011.06.003
} 
For an inventory or supply chain system, inflation plays a very significant role in deciding optimal policies now-a-days. Inflation was not usually considered as a major factor in the earlier models because of its negligible impacts on prices, especially when the time cycle is very short and inflation rate is very low. However, in the present day global scenario, economic growth of a country is affected not only by its own economic policy but also by other countries' economic health. For example, the incident of 9/11 had a huge impact on USA's economy; at the same time, it affected other country's economy too. Due to high inflation, financial situations of many developing countries have been changed. Though its effect is seen prominent over the past few decades only, its long since theoretical research has been done over this particular issue. Buzacott (1975), Bierman and Thomas (1977) and Misra (1979a) are some among the pioneers who investigated the inventory decisions under inflationary condition in a standard EOQ framework. However, it is always better to consider time value of money separately while considering inflation, as the value of money also changes over time. In most of the cases, this change is not due to inflation only; some other issues play vital role in changing the real value of money over time. Misra (1979b) and Chandra and Bahner (1985) developed models to investigate the effects of inflation and time value of money on optimal ordering policies. Datta and Pal (1991) developed a model with linear time-dependent demand and shortages to investigate the effects of inflation and time value of money on a finite horizon policy. Sarker et al. (1994) studied an ordering policy for deteriorating items with allowable shortage and permissible delay in payment under inflation. Bose et al. (1995) studied an EOQ model for deteriorating items with linear time-dependent demand rate and shortages under inflation and time discounting. Moon et al. (2005) studied EOQ models for ameliorating/deteriorating items under inflation and time discounting. All the above works have been done on inventory modeling. A large number of inventory models dealing with inflation and time value of money are available in the literature. However, the literature is scarce as far as the supply chain model is concerned. Sarkar et al. (2000) developed a model for perishable product under inflation and permissible delay in payment, incorporating the concept of inflation and time discounting of money.

In this article, we develop a single-buyer single-manufacturer supply chain model considering inflation at the buyer and, at the same time, deflation at the manufacturer. The manufacturer fulfills the buyer's total demand over a finite time horizon by producing a number of lots. The model is formulated and a methodology for finding the optimal solution of the model is developed. The paper is organized as follows: Section 2 gives the assumptions and notations. Section 3 is devoted to the model development. Section 4 presents the solution methodology of the model. In Section 5, the model is illustrated numerically and the sensitivity analysis is carried out for a chosen data set. Finally, in Section 6, the paper is concluded and some future research directions are given.

\section{Assumption and Notations}

The following assumptions are adopted to develop the model:

(i) The supply chain under consideration comprises of a single manufacturer and a single buyer for a single product.

(ii) The buyer's demand rate is deterministic and replenishment rate is infinite.

(iii) Replenishment lead time is known and fixed.

(iv) The manufacturer produces a number of lots, the sum of which is equal to the buyer's total demand over a time horizon and the manufacturer's each production lot is delivered to the buyer in $n$ shipments.

(v) The manufacturer's production rate is infinite.

(vi) The buyer takes account of inflation whereas the manufacturer takes account of deflation i.e. negative inflation.

We use the following set of notations throughout the paper.

$D$ : demand rate at the buyer

$h_{b}:$ buyer's holding cost in Rs/unit/unit time

$h_{m}:$ manufacturer's holding cost in Rs/unit/unit time 
$S_{b}: \quad$ buyer's ordering cost in Rs/order

$S_{m}:$ manufacturer's set up cost in Rs/set up

$f_{b}:$ inflation rate at the buyer

$f_{m}:$ deflation rate at the manufacturer

$Q$ : order quantity of the buyer

$r$ : discount rate representing the time value of money

$T$ : buyer's replenishment time interval

$N$ : number of complete cycles of the buyer during the time horizon of one year

$n$ : ratio of the manufacturer's lot size to the buyer's ordering quantity, a positive integer

$T^{*}: \quad$ optimal value of $T$

$N^{*}: \quad$ optimal value of $N$

$n^{*}: \quad$ optimal value of $n$

$R_{1}: f_{b}-r$, present value of the nominal inflation rate at the buyer

$R_{2}: f_{m}-r$, present value of the nominal deflation rate at the manufacturer

$T C$ : present value of the total cost per unit time of the supply chain

The configurations of the buyer's and manufacturer's inventories are shown in Fig. 1.

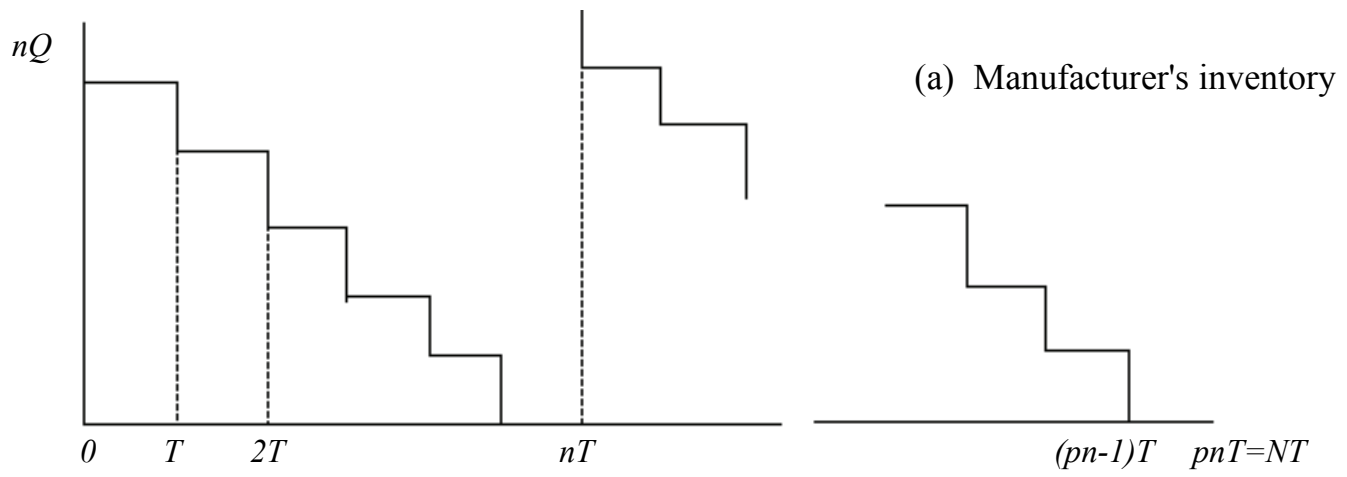

(b) Buyer's inventory

$Q$

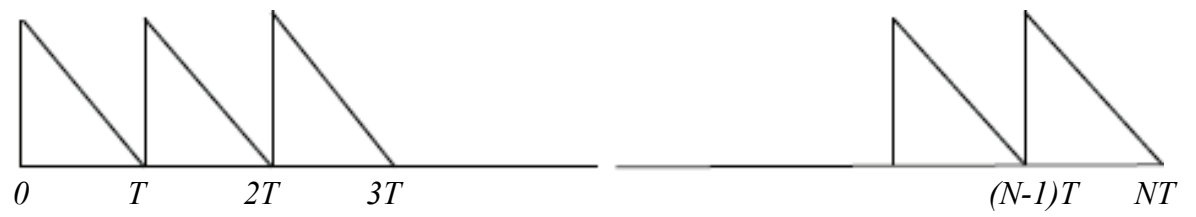

Fig. 1. Manufacturer's and buyer's inventories

\section{The Model}

\subsection{Buyer's costs}

Let us suppose that the buyer places orders at times $t=0, T, 2 T, \ldots,(N-1) T$. So the present value of the inflated ordering costs for $N$ successive orders will be $S_{b}, S_{b} e^{R_{1} T}, \ldots, S_{b} e^{(N-1) R_{1} T}$ respectively. Hence, the present value of the total ordering costs of the buyer during a year $(N T=1)$ is given by

$S_{b}\left(1+e^{R_{1} T}+e^{2 R_{1} T}+\cdots+e^{(N-1) R_{1} T}\right)=s_{b}\left(\frac{e^{R_{1}}-1}{e^{R_{1} T}-1}\right)$

The number of items held by the buyer at any time instance $t$ in the $i$-th cycle, $(i-1) T<t<i T, i=1$, $2, \ldots, N$, is equal to the total demand of the remaining time of the $i$-th cycle which is equal to $D(i T-t)$. Therefore, the present value of the inflated holding cost at time $t$ in the $i$-th cycle is $h_{b} D(i T-t) e^{R_{1} t}$. Hence, the present value of the inflated holding cost of the buyer during a year $(N T=1)$ is given by

$$
\sum_{i=1}^{N} h_{b} D \int_{(i-1) T}^{i T}(i T-t) e^{R_{1} t} d t=\frac{h_{b} D}{R_{1}^{2}} \sum_{i=1}^{N}\left[e^{i R_{1} T}-e^{(i-1) R_{1} T}-T R_{1} e^{(i-1) R_{1} T}\right]=\frac{h_{b} D}{R_{1}^{2}}\left(\frac{e^{R_{1}}-1}{e^{R_{1} T}-1}\right)\left[e^{R_{1} T}-R_{1} T-1\right]
$$

Summing up Eq. (1) and Eq. (2), the present value of the total cost of the buyer during a year is given by 
$T C_{1}(T)=\left(\frac{e^{R_{1}}-1}{e^{R_{1} T}-1}\right)\left[S_{b}+\frac{h_{b} D}{R_{1}^{2}}\left(e^{R_{1} T}-R_{1} T-1\right)\right]$.

\subsection{Manufacturer's costs}

Suppose that $p$ set-ups are required by the manufacturer in order to meet the demand of the buyer for $N$ cycles during a year. Then, we have,

$p n=N$,

where $n$ is a positive integer representing the ratio to the manufacturer's shipment size to the buyer's ordering quantity. The manufacturer's $p$ set-ups will take place at times $0, n T, 2 n T, \ldots,(p-1) n T$ and the corresponding set up costs, under deflation, will be $S_{m}, S_{m} e^{n R_{2} T}, S_{m} e^{2 n R_{2} T}, \ldots, S_{m} e^{(p-1) n R_{2} T}$ respectively. Hence, the present value of the total set up costs of the manufacturer during a year $(N T=1)$ is

$S_{m}\left(1+e^{n R_{2} T}+\ldots+e^{(p-1) n R_{2} T}\right)=S_{m}\left(\frac{e^{R_{2}}-1}{e^{n R_{2} T}-1}\right)$

We calculate the present value of the holding cost as follows. In the time interval $[0, n T]$, the inventory level at the manufacturer at time $t,(i-1) T<t<i T, i=1,2, \ldots, n$ is $(n-i) Q$. Therefore, the deflated holding cost of the manufacturer at time $t$ is $h_{m}(n-i) Q e^{R_{2} t}$. Hence, the present value of the holding costs in $[0, n T]$ is

$\sum_{i=1}^{n} h_{m}(n-i) Q \int_{(i-1) T}^{i T} e^{R_{2} t} d t=\frac{h_{m} Q}{R_{2}}\left[\frac{e^{n R_{2} T}-1}{e^{R_{2} T}-1}-n\right]$.

Hence, the present value of the total holding cost of the manufacturer during the time interval $[0, N T]$ is given as follow,

$$
\frac{h_{m} Q}{R_{2}}\left[\frac{e^{n R_{2} T}-1}{e^{R_{2} T}-1}-n\right]\left[1+e^{n R_{2} T}+\ldots+e^{(p-1) n R_{2} T}\right]=\frac{h_{m} D T}{R_{2}}\left[\frac{e^{R_{2}}-1}{e^{R_{2} T}-1}-\frac{n\left(e^{R_{2}}-1\right)}{e^{n R_{2} T}-1}\right] .
$$

Using Eq. (5) and Eq. (7), the present value of the total cost of the manufacturer during a year $(N T=$ $1)$ is given by

$$
T C_{2}(n, T)=\left(e^{R_{2}}-1\right)\left[\frac{S_{m}}{e^{n R_{2} T}-1}+\frac{h_{m} D T}{R_{2}}\left\{\frac{1}{e^{R_{2} T}-1}-\frac{n}{e^{n R_{2} T}-1}\right\}\right]
$$

\subsection{Total cost of the supply chain}

The present value of the total cost of the entire supply chain during a year $(N T=1)$ is, therefore, given by

$$
\begin{aligned}
T C(n, T)=T C_{l}(T)+T C_{2}(n, T) & =\left(\frac{e^{R_{1}}-1}{e^{R_{1} T}-1}\right)\left[S_{b}+\frac{h_{b} D}{R_{1}^{2}}\left(e^{R_{1} T}-R_{1} T-1\right)\right] \\
& +\left(e^{R_{2}}-1\right)\left[\frac{S_{m}}{e^{n R_{2} T}-1}+\frac{h_{m} D T}{R_{2}}\left\{\frac{1}{e^{R_{2} T}-1}-\frac{n}{e^{n R_{2} T}-1}\right\}\right] .
\end{aligned}
$$

\section{Solution Methodology}

The total cost $T C(n, T)$ is a function of discrete variable $n$ and continuous variable $T$. For a given positive integer $n, \frac{\partial T C}{\partial T}=0$ gives, 


$$
\begin{aligned}
& \frac{\left(e^{R_{1}}-1\right) h_{b} D}{R_{1}}+\frac{\left(e^{R_{1}}-1\right)}{\left(e^{R_{1} T}-1\right)^{2}}\left(h_{b} D T-S_{b} R_{1}\right) e^{R_{1} T}-\frac{\left(e^{R_{1}}-1\right)}{\left(e^{R_{1} T}-1\right)} \frac{h_{b} D}{R_{1}}+\left(e^{R_{2}}-1\right) \\
& \times\left[\frac{n e^{n R_{2} T}\left(n h_{m} D T-S_{m} R_{2}\right)}{\left(e^{n R_{2} T}-1\right)^{2}}+\frac{h_{m} D}{R_{2}\left(e^{R_{2} T}-1\right)}-\frac{h_{m} D T e^{R_{2} T}}{\left(e^{R_{2} T}-1\right)^{2}}-\frac{n h_{m} D}{R_{2}\left(e^{n R_{2} T}-1\right)}\right]=0 .
\end{aligned}
$$

Applying a line search on $n$ and an one dimensional search technique on Eq. (10), we can numerically find the optimal solution $\left(n^{*}, T^{*}\right)$ which minimizes $T C(n, T)$. However, the solution obtained in this way may not be feasible because of the following reasons:

(a) The value of $T^{*}$ must satisfy the relation $N^{*} T^{*}=1$ for some positive integer $N^{*}$.

(b) $N^{*}$ should be a multiple of $n^{*}$ (see Eq. (4)).

In order to satisfy (a) and (b), we do the following adjustments in the optimal decisions:

(i) For each $T^{*}$, there corresponds the greatest positive integer $N_{1}$ such that $n^{*}$ divides $N_{1}$ and $N_{1} T^{*}<$

1 and the least positive integer $N_{2}$ such that $n^{*}$ divides $N_{2}$ and $N_{2} T^{*}>1$.

(ii) For $N_{1}$ and $N_{2}$, adjust the value of $T^{*}$ as $T_{1}^{*}$ and $T_{2}^{*}$ such that $N_{1} T_{1}^{*}=1$ and $N_{2} T_{2}^{*}=1$.

(iii)Calculate $T C\left(N_{1}, T_{1}^{*}\right)$ and $T C\left(N_{2}, T_{2}^{*}\right)$.

(iv) Set the adjusted values of $T^{*}$ and $N^{*}$ as follows:

$$
\begin{aligned}
& T_{a}^{*}=T_{1}^{*} \text { and } N_{a}^{*}=N_{1} \text { if } \operatorname{TC}\left(N_{1}, T_{1}^{*}\right)<T C\left(N_{2}, T_{2}^{*}\right) \\
& T_{a}^{*}=T_{2}^{*} \text { and } N_{a}^{*}=N_{2} \text { if } \operatorname{TC}\left(N_{1}, T_{1}^{*}\right)>T C\left(N_{2}, T_{2}^{*}\right)
\end{aligned}
$$

\section{Numerical Example}

To illustrate the developed model, we consider the parameter values as follows: $S_{b}=\mathrm{Rs} 400 /$ order, $h_{b}=$ Rs 18/unit/unit time, $S_{m}=$ Rs $1600 /$ set up, $h_{m}=$ Rs 10/unit/unit time, $R_{1}=0.75, R_{2}=0.05$. For D=1000 units and 2000 units, we find the minimum total cost of the supply chain as Rs 9847.5 and Rs

\begin{tabular}{|c|c|c|c|c|c|c|c|}
\hline \multirow[b]{2}{*}{$R_{1}$} & \multirow[b]{2}{*}{$R_{2}$} & \multicolumn{3}{|c|}{$D=1000$} & \multicolumn{3}{|c|}{$D=2000$} \\
\hline & & $n^{*}$ & $T^{*}$ & $T C^{*}$ & $n^{*}$ & $T^{*}$ & $T C^{*}$ \\
\hline \multirow{5}{*}{0.45} & 0.40 & 2 & 0.3020 & 9540.6 & 2 & 0.2113 & 13763.3 \\
\hline & 0.25 & 2 & 0.2959 & 9353.4 & 2 & 0.2076 & 13419.3 \\
\hline & 0.05 & 2 & 0.2884 & 9119.1 & 2 & 0.2029 & 12992.3 \\
\hline & -0.10 & 2 & 0.2832 & 8954.7 & 2 & 0.1997 & 12697.6 \\
\hline & -0.25 & 2 & 0.2784 & 8799.6 & 2 & 0.1966 & 12423.3 \\
\hline \multirow{5}{*}{0.60} & 0.40 & 2 & 0.2995 & 9890.9 & 2 & 0.2093 & 14294.7 \\
\hline & 0.25 & 2 & 0.2935 & 9702.1 & 2 & 0.2056 & 13944.4 \\
\hline & 0.05 & 2 & 0.2863 & 9466.1 & 2 & 0.2011 & 13514.5 \\
\hline & -0.10 & 2 & 0.2812 & 9300.5 & 2 & 0.1980 & 13218.0 \\
\hline & -0.25 & 2 & 0.2766 & 9144.3 & 2 & 0.1950 & 12942.2 \\
\hline \multirow{5}{*}{0.75} & 0.40 & 2 & 0.2970 & 10275.7 & 2 & 0.2072 & 14875.2 \\
\hline & 0.25 & 2 & 0.2912 & 10085.0 & 2 & 0.2037 & 14522.4 \\
\hline & 0.05 & 2 & 0.2842 & 9847.5 & 2 & 0.1993 & 14089.7 \\
\hline & -0.10 & 2 & 0.2793 & 9680.5 & 2 & 0.1963 & 13791.4 \\
\hline & -0.25 & 2 & 0.2749 & 9523.4 & 2 & 0.1935 & 13514.0 \\
\hline \multirow{5}{*}{0.90} & 0.40 & 2 & 0.2944 & 10698.6 & 2 & 0.2052 & 15514.8 \\
\hline & 0.25 & 2 & 0.2839 & 10506.5 & 2 & 0.2017 & 15159.8 \\
\hline & 0.05 & 2 & 0.2820 & 10266.8 & 2 & 0.1975 & 14724.0 \\
\hline & -0.10 & 2 & 0.2774 & 10098.8 & 2 & 0.1946 & 14423.8 \\
\hline & -0.25 & 2 & 0.2731 & 9940.7 & 2 & 0.1919 & 14144.7 \\
\hline \multirow{5}{*}{1.05} & 0.40 & 2 & 0.2919 & 11164.9 & 2 & 0.2031 & 16220.4 \\
\hline & 0.25 & 2 & 0.2865 & 10970.4 & 2 & 0.1998 & 15862.0 \\
\hline & 0.05 & 2 & 0.2800 & 10728.7 & 2 & 0.1957 & 15424.0 \\
\hline & -0.10 & 2 & 0.2755 & 10559.0 & 2 & 0.1929 & 15122.0 \\
\hline & -0.25 & 2 & 0.2714 & 10400.5 & 2 & 0.1903 & 14841.2 \\
\hline
\end{tabular}
14089.7, respectively. Computational results for different values of $R_{1}$ and $R_{2}$ are shown in Table 1 .

\section{Table 1}

Variation of the optimal results for different values of $R_{1}$ and $R_{2}$ 
The adjusted optimal results are presented in Table 2.

Table 2

Variation of the optimal results (adjusted) for different values of $R_{1}$ and $R_{2}$

\begin{tabular}{cllllccccc}
\hline & & \multicolumn{7}{c}{$D=1000$} & \multicolumn{7}{c}{$D=2000$} \\
$n_{1}$ & $R_{2}$ & $n^{*}$ & $N_{a}^{*}$ & $T_{a}^{*}$ & $T C_{a}^{*}$ & $n^{*}$ & $N_{a}^{*}$ & $T_{a}^{*}$ & $T C_{a}^{*}$ \\
\hline \multirow{4}{*}{0.45} & 0.40 & 2 & 4 & 0.25 & 9711.84 & 2 & 4 & 0.25 & 13960 \\
& 0.25 & 2 & 4 & 0.25 & 9486.2 & 2 & 4 & 0.25 & 13650 \\
& 0.05 & 2 & 4 & 0.25 & 9211.7 & 2 & 6 & 0.1667 & 13243 \\
& -0.10 & 2 & 4 & 0.25 & 9023.8 & 2 & 6 & 0.1667 & 12904 \\
& -0.25 & 2 & 4 & 0.25 & 8850.0 & 2 & 6 & 0.1667 & 12592 \\
\hline \multirow{5}{*}{0.60} & 0.40 & 2 & 4 & 0.25 & 10052.0 & 2 & 4 & 0.25 & 14518 \\
& 0.25 & 2 & 4 & 0.25 & 9827.0 & 2 & 4 & 0.25 & 14208 \\
& 0.05 & 2 & 4 & 0.25 & 9552.0 & 2 & 6 & 0.1667 & 13752 \\
& -0.10 & 2 & 4 & 0.25 & 9364.0 & 2 & 6 & 0.1667 & 13413 \\
& -0.25 & 2 & 4 & 0.25 & 9190.0 & 2 & 6 & 0.1667 & 13101 \\
\hline \multirow{5}{*}{0.75} & 0.40 & 2 & 4 & 0.25 & 10427.0 & 2 & 4 & 0.25 & 15134 \\
& 0.25 & 2 & 4 & 0.25 & 10202 & 2 & 6 & 0.1667 & 14814 \\
& 0.05 & 2 & 4 & 0.25 & 9927.0 & 2 & 6 & 0.1667 & 14314 \\
& -0.10 & 2 & 4 & 0.25 & 9739.0 & 2 & 6 & 0.1667 & 13974 \\
& -0.25 & 2 & 4 & 0.25 & 9565.0 & 2 & 6 & 0.1667 & 13662 \\
\hline \multirow{5}{*}{0.90} & 0.40 & 2 & 4 & 0.25 & 10841.0 & 2 & 4 & 0.25 & 15813 \\
& 0.25 & 2 & 4 & 0.25 & 10615.0 & 2 & 6 & 0.1667 & 15435 \\
& 0.05 & 2 & 4 & 0.25 & 10340.0 & 2 & 6 & 0.1667 & 14934 \\
& -0.10 & 2 & 4 & 0.25 & 10153.0 & 2 & 6 & 0.1667 & 14595 \\
& -0.25 & 2 & 4 & 0.25 & 9979.0 & 2 & 6 & 0.1667 & 14283 \\
\hline \multirow{6}{*}{1.05} & 0.40 & 2 & 4 & 0.25 & 11297.0 & 2 & 6 & 0.1667 & 16536 \\
& 0.25 & 2 & 4 & 0.25 & 11071.0 & 2 & 6 & 0.1667 & 16121 \\
& 0.05 & 2 & 4 & 0.25 & 10796.0 & 2 & 6 & 0.1667 & 15621 \\
& -0.10 & 2 & 4 & 0.25 & 10609.0 & 2 & 6 & 0.1667 & 15282 \\
& -0.25 & 2 & 4 & 0.25 & 10435.0 & 2 & 6 & 0.1667 & 14970 \\
\hline
\end{tabular}

We now investigate the effects of changes in the model-parameters on the optimal decisions and explore the underlying behavioral pattern of the model.

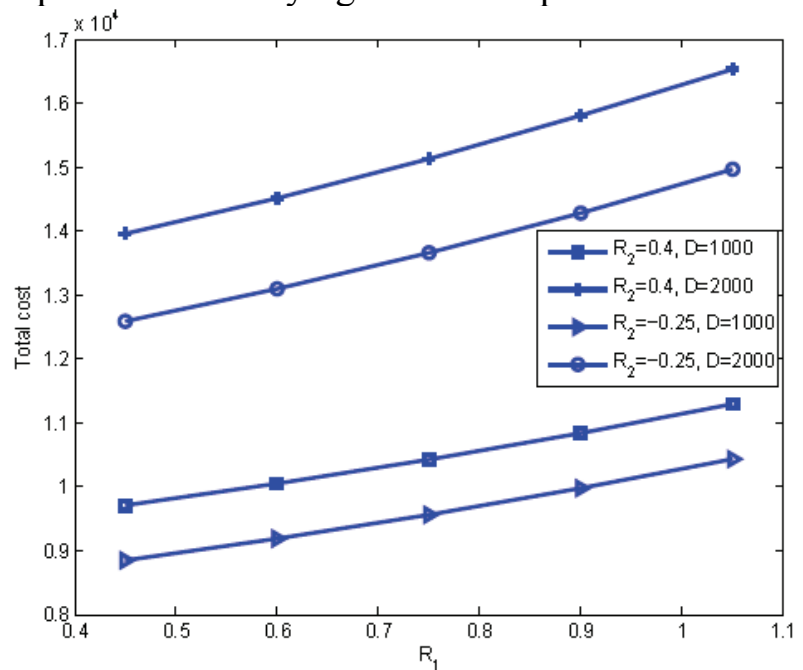

Fig. 2. Variation of the total cost with $R_{1}$

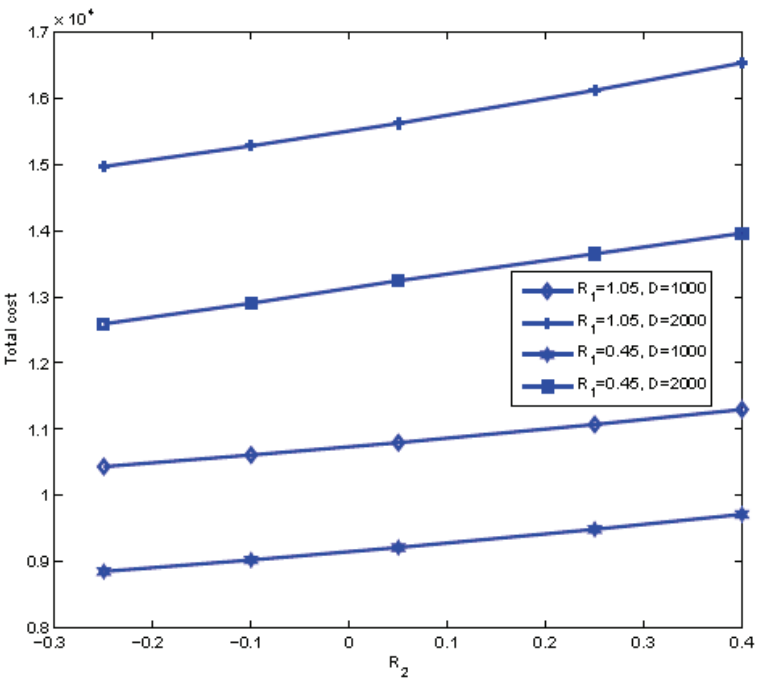

Fig. 3. Variation of the total cost with $R_{2}$ 


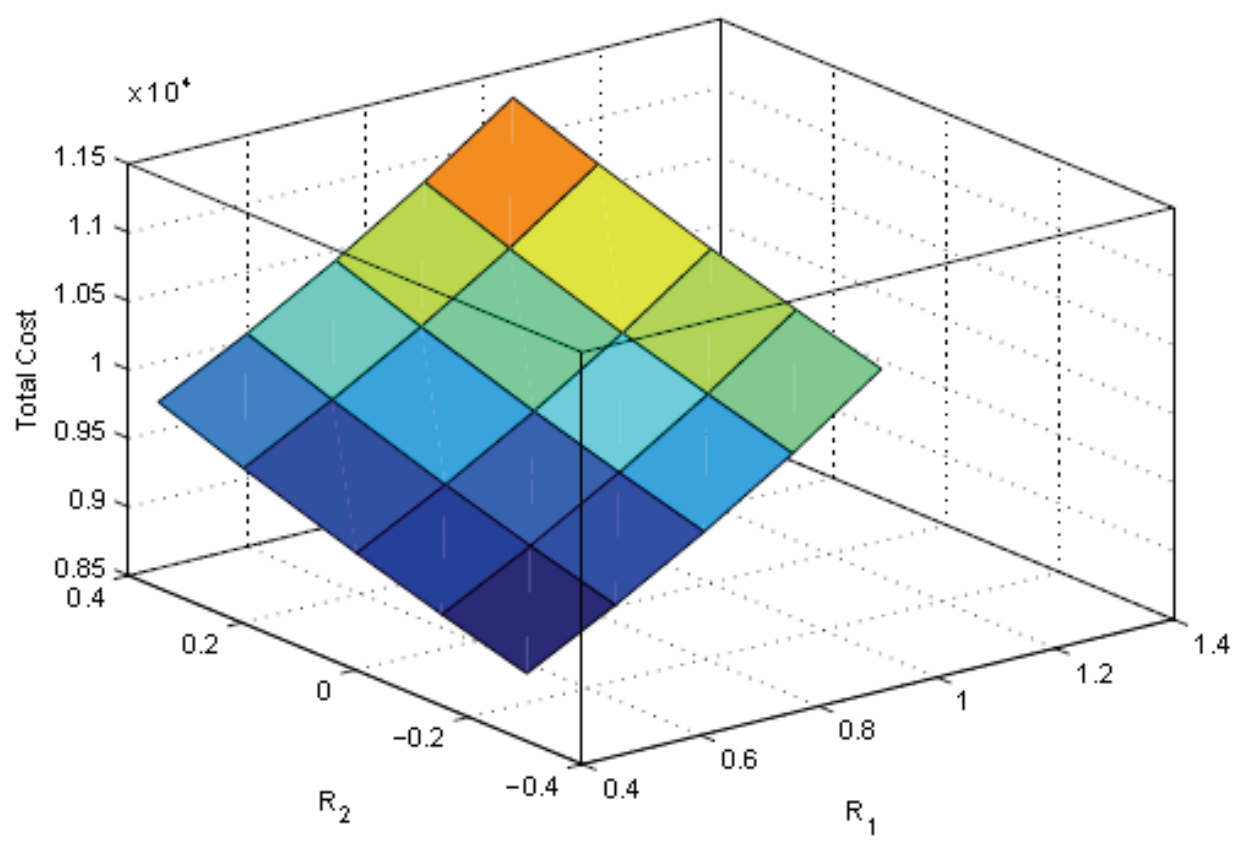

Fig. 4. Variation of the total cost with $R_{1}$ and $R_{2}$ (when $\mathrm{D}=1000$ )

Fig. 2 and Fig. 3 show the effects of changes in the total cost with respect to the parameters $R_{1}$ and $R_{2}$, respectively. Fig. 2 shows that the total cost increases as the inflation rate at the buyer increases whereas Fig. 3 shows that the total cost increases as the deflation rate at the manufacturer increases. These observations satisfy our intuition and are consistent with reality. It is also noted that for particular values of $R_{1}$ and $R_{2}$, the total cost increases as demand increases. Fig. 4 indicates that the total cost increases with respect to the increment in both $R_{1}$ and $R_{2}$, for a particular demand. The total cost of the supply chain increases with higher demand. This is due to the fact that the total cost varies directly with the market demand, which is evident from Eq. (9).

\section{Conclusions}

In this paper, we have developed a two echelon (single-buyer single-manufacturer) supply chain model taking into account inflation at the buyer and at the same time deflation at the manufacturer. The model is formulated based on the assumption that the manufacturer produces a number of lots, the sum of which is equal to the buyer's total demand over a finite time horizon and the manufacturer's each production lot is delivered to the buyer in $n$ shipments. For a chosen data set, numerical solution along with necessary adjustments have been provided to exhibit the feasibility of the solution. In our model, the demand is taken as a known constant. However, future research may relax this assumption and consider other demand patterns or factors that influence the market demand. The problem under consideration may also be studied to consider a three level supply chain along with coordination mechanisms that effectively enhance supply chain performance.

\section{Acknowledgment}

The second author gratefully acknowledges the financial support provided by the University Grants Commission (UGC), New Delhi, India. 


\section{References}

Banerjee, A. (1986). A joint economic-lot-size model for purchaser and vendor. Decision Sciences, 17, 292-311.

Bierman, H. \& Thomas, J. (1977). Inventory decisions under inflationary condition. Decision Sciences, 8(7), 151-155.

Bose, S., Goswami, A. \& Chaudhuri, K.S. (1995). An EOQ model for deteriorating items with linear time-dependent demand rate and shortages under inflation and time discounting. Journal of the Operational Research Society, 46(6), 771-782.

Buzacott, J.A. (1975). Economic order quantities with inflation. Operational Research Quarterly, 26(3), 553-558.

Chandra, M.J. \& Bahner, M.L. (1985). The effects of inflation and time value of money on some inventory systems. International Journal of Production Research, 23(4), 723-729.

Datta, T.K. \& Pal, A.K. (1991). Effects of inflation and time value of money on an inventory model with linear time dependent demand rate and shortages. European Journal of Operational Research, 52(2), 326-333.

Goyal, S.K. (1976). An integrated inventory model for a single-supplier single-customer problem. International Journal of Production Research, 15(1), 107-111.

Goyal, S.K. (1988). A joint economic lot-size model for purchaser and vendor: a comment. Decision Sciences 19, 236-241.

Goyal, S.K. (1995). A one-vendor multi-buyer integrated inventory model: a comment. European Journal of Operational Research, 82, 209-210.

Hill, R.M. (1997). The single-vendor single-buyer integrated production-inventory model with a generalized policy. European Journal of Operational Research, 97, 493-499.

Lu, L. (1995). A one-vendor multi-buyer integrated inventory model. European Journal of Operational Research, 81, 312-323.

Misra, R.B. (1979a). A study of inflation effects on inventory system. Logistics Spectrum, 9(3), 260268.

Misra, R.B. (1979b). A note on optimal inventory management under inflation. Naval Research Logistics, 26(1), 161-165.

Moon, I., Giri, B.C. \& Ko, B. (2005), EOQ models for ameliorating/deteriorating items under inflation and time discounting. European Journal of Operational Research, 162, 773-785.

Sarker, B.R. \& Pan, H. (1994). Effects of inflation and the time value of money on order quantity and allowable shortage. International Journal of Production Economics, 34(1), 65-72.

Sarker, B.R., Jamal, A.M.M. \& Wang, S. (2000). Supply chain models for perishable products under inflation and permissible delay in payment. Computers \& Operations Research, 27, 59-75. 